\title{
ОСОБЕННОСТИ ДИСТАНЦИОННОГО ОБУЧЕНИЯ ИНОСТРАННОМУ ЯЗЫКУ СТУДЕНТОВ НЕЯЗЫКОВЫХ ВУЗОВ
}

\section{FEATURES OF DISTANCE LEARNING OF A FOREIGN LANGUAGE FOR STUDENTS OF NON-LINGUISTIC UNIVERSITIES}

\section{S. Levicheva \\ O. Levichev}

Summary: Recently, in the information age, the search for innovative solutions in teaching a foreign language is more important. The needs of students are what determine the goals and objectives of teaching. The main goal pursued by students of non-linguistic universities is to obtain professional knowledge in a foreign language. The use of Internet resources helps students to achieve greater efficiency in independent work in a limited time (creating a full-fledged language environment, quick and easy access to information, means of communication with native speakers, etc.) The purpose of distance learning of a foreign language for students of non-linguistic universities in its most general form is, first of all, teaching listening and speaking in the oral form of communication in the language being studied. The authors of the article come to the conclusion that the effectiveness of distance learning is one of the factors that allows students to keep more information in their memory, expand their awareness and achieve better results in their work.

Keywords: foreign language, distance learning, non-philological education, pre-university education, students of non-linguistic universities, internet.
Левичева Светлана Викторовна

К.филол.н., дочент, Московский авиационный институт (Национальный исследовательский университет) parabola.08@mail.ru

Левичев Олег Анатольевич

К.воен.н., доцент, Государственный университет по землеустройству (2. Москва) info@guz.ru

Аннотация: За последнее время, в информационную эпоху, поиск инновационных решений в обучении иностранному языку становится более важным. Потребности студентов - это то, что определяет цели и задачи преподавания. Основной целью, преследуемой студентами неязыковых вузов, является получение профессиональных знаний на иностранном языке. Использование интернет-ресурсов помогает студентам добиться большей результативности в самостоятельной работе в ограниченные сроки (создание полноценной языковой среды, быстрый и легкий доступ к информации, средства общения с носителями языка и т.д.). Целью дистанционного обучения иностранному языку студентов неязыковых вузов в его наиболее общей форме является, в первую очередь, обучение аудированию и говорению в устной форме общения на изучаемом языке. Авторы статьи приходят к выводу, что эффективность дистанционного обучения является одним из факторов, который позволяет слушателям сохранять больше информации в своей памяти, расширять свою осведомленность и достигать лучших результатов в своей работе.

Ключевые слова: иностранный язык, дистанционное обучение, нефилологическое образование, довузовское образование, студенты неязыковых вузов, интернет.

ключевым направлением образования в 21 веке.

Внедрение современных информационных технологий, таких как Интернет, различные мультимедийные устройства, электронные учебные ресурсы, множество аудио-видео комплексов вывели систему обучения иностранному языку на новый уровень.

В последнее десятилетия в России особое внимание уделяется информатизации системе образования [4]. Следует отметить, что на различных уровнях - от федерального до отраслевого - реализуются обширные программы, направленные на решение поставленных педагогами задач, а также большие усилия направлены на создание единого образовательного информационного пространства, создание электронных образовательных ресурсов, повышение квалификации педагогов в области применения и внедрения в организацию учебного процесса информационных технологий, возможности применения которых в обучении иностранным языкам отражены в работах многих исследователей [3]. 
Преимущества использования информационных технологий по сравнению с традиционными методами выражаются в сочетании четкости аудио-видео, возможности использования интерактивной доски, обеспечении результативности восприятия и запоминания учебного материала, экономии учебного времени [6].

Таким образом, дистанционное обучение онлайн - это самостоятельная система со специфическим содержанием, организационными формами, принципами, средствами и процессом онлайн-обучения.

Сегодня большинство изучающих иностранный язык обучаются по программам, не связанным с филологией.

Современные исследования показывают, что использование Интернета позволяет создать соответствующую иноязычную среду, ставить и выполнять задачи по развитию потребности студентов в изучении иностранного языка путем активного общения на нем с носителями языка и работы со всеми видами аутентичных справочных материалов. Учитывая важность эффективной, быстрой и легкодоступной коммуникации, Интернет можно использовать в качестве средства получения информации, общения и обучения. К сожалению, большая часть информации в Интернете представлена неорганизованно, что снижает ее эффективность при использовании. Необходимы дополнительные исследования, чтобы в полной мере использовать ресурсы для обучения языкам в Интернете с учетом потребностей студентов и целей обучения.

Большой интерес представляют компьютерные языковые курсы, предлагаемые студентам, неязыковых вузов. Многофакторное описание всего, что может предложить компьютер как новый образовательный инструмент, разработка основы для электронного учебника, использование гипертекстовых технологий в обучении языку, лингвистический анализ различных компьютерных курсов доказывают, что современные технологии играют значительную роль в учебном процессе.

Преимущества новых форм дистанционного обучения перед традиционными заключаются в их эффективности, возможности быстрой и эффективной творческой самореализации студентов за счет нового качества учебных материалов. В новых программах учащемуся отводится все более активная роль, которая дает свободу выбора действий и получения индивидуальных результатов.

В дополнение к преимуществам и удобствам, упомянутым выше в дистанционном обучении, можно столкнуться с некоторыми проблемами. Прежде всего, желательно выбрать метод, который подходит и специфичен для процесса дистанционного обучения. В силу того, что действенность и успех любой системы образования зависит от используемых методов. Метод обучения - это метод взаимодействия преподавателей и студентов, направленный на достижение образовательных целей на современном уровне. К числу наиболее эффективных подходов к обучению иностранному языку студентов неязыковых вузов относятся методы обучения языку в дистанционном обучении с использованием информационно-коммуникационных технологий.

Выбор интерактивного метода дистанционного обучения иностранным языкам - хорошая идея ввиду того, что интерактивный метод обучения служит активизации усвоения знаний учащимися, развитию личностных качеств за счет повышения активности между учащимися и преподавателем в учебном процессе. Использование интерактивных методов может помочь повысить эффективность урока [2]. Основными критериями интерактивного обучения являются: неформальные дискуссии, возможность свободно излагать учебный материал, небольшое количество лекций, но большое количество семинаров, возможности для студентов проявлять инициативу, малая группа, классные задания, письменные задания и другие методы, которые играют особую роль в повышении результативности воспитательной работы. Имея это ввиду, можно сказать следующее, интерактивный метод приводит ко многим положительным результатам в процессе дистанционного обучения иностранным языкам.

Использование интерактивных методов в процессе дистанционного обучения иностранным языкам расширяет участие студентов, стимулирует их к достижению максимальных результатов. Интерактивность также помогает учителям включать в курс более сложные материалы. Интерактивность может сочетаться с имитацией среды, в которой учащиеся должны ознакомиться с процессом обучения. Например, если курс предполагает использование компьютерной программы, изображения на экране должны соответствовать изображениям, которые должны отображаться при запуске программы. Студентам следует дать задание сделать что-то, что имеет отношение к одной из изучаемых тем. Для более сложных тем, можно смоделировать бизнес-процесс и побудить читателя двигаться дальше [5].

Стоит сказать, что единой системы понимания сущности дистанционного обучения не существует. Однако, в настоящее время, дистанционное обучение в высших учебных заведениях представлено в виде технологии дистанционного обучения, которая не подкреплена нормативно-правовой базой.

Основной целью использования интерактивных методов в дистанционном обучении иностранным языкам 
является вовлечение студентов в процесс активного обучения, оказание им помощи в развитии знаний и исследовательских навыков. Интерактивные методы основаны на активных отношениях между учителем и учеником, полном понимании друг друга. Конечной целью внедрения интерактивных методов в учебный процесс, является организация сотрудничества между учителем и учеником в классе, независимо от того, какую форму принимает урок. Учителю необходимо вовлечь учащихся в проблемы урока, активизировать их движение и научить их овладевать в результате.

Интерактивный метод дистанционного обучения становится самым необходимым методом в современном мире. Например, можно высказывать свое мнение по определенной теме, и узнать отношение и мнение окружающих, делиться идеями в Интернете не только со знакомыми, но и с другими пользователями. Представители разных национальностей могут выражать разные мнения, и вследствие этого, можно сделать общий вывод. Интерактивный метод также может помочь сделать тему более понятной. Обратная связь - это выбор конкретной темы.

Преимуществом использования интерактивных методов в дистанционном обучении иностранным языкам, можно назвать то, что это прежде всего, приводит к лучшему овладению содержанием обучения. Со временем устанавливается образовательная коммуникация между учеником-учителем-учеником. учебный материал лучше всего запоминается благодаря взаимной информации, поиску и обработке [1]. Студенты развивают навыки общения, самовыражения и обмена идеями. Каждый студент способен самостоятельно мыслить, работать и наблюдать. На интерактивных уроках ученик не только осваивает содержание образования, но и развивает свое критическое и логическое мышление.

Таким образом, дистанционное образование - это новый метод в системе образования нашей страны, и сегодня этому процессу уделяется серьезное внимание. Во всех университетах есть компьютерные классы, большинство из которых подключены к глобальному Интернету.
Дистанционное обучение имеет следующие преимущества.

1. Творческая среда обучения. Есть много способов, которыми учитель может преподавать, а ученики могут читать только данный материал [7]. На основе предлагаемого дистанционного обучения студенты сами ищут необходимую информацию в компьютерной базе данных и следят за тем, чтобы их опыт хорошо передавался другим, а также работали над собственным образованием.

2. Возможность самостоятельного обучения. Дистанционное обучение включает в себя начальную, среднюю, высшую и высшую подготовку. Преподаватели с разным уровнем подготовки, могут работать над своими собственными планами уроков и взаимодействовать со студентами на своем уровне.

3. Большие перемены на рабочем месте. Дистанционное обучение обеспечивает лучшие условия для миллионов людей, особенно молодых людей, которые учатся, не отрываясь от работы. Этот тип обучения играет важную роль в обучении.

4. Новый и эффективный инструмент для преподавания и обучения. Преимущество студентов, обучающихся на этой основе, заключается в том, что они обеспечены лучшими, высококачественными материалами и преподавателями.

Однако стоит отметить, что успех и качество дистанционного обучения во многом зависит не только от эффективности организации и качества используемых учебных материалов, но и от лидерства и мастерства преподавателей, принимающих участие в этом процессе.

Исходя из вышесказанного, можно сделать вывод, что перспективы обучения в первую очередь связаны с развитием его дистанционных форм. Однако, учитывая все эти преимущества, следует отметить, что, в частности, при подготовке специалистов в высших учебных заведениях дистанционное обучение не должно конкурировать с традиционным подходом, а скорее дополнять и расширять его.

\section{ЛИТЕРАТУРА}

1. Волкова В.В. Внедрение дистанционного обучения иностранному языку в неязыковых вузах. // В Сб. статей по итогам межд. науч.-практ. конф. «Теории, школы и концепции устойчивого развития науки в современных условиях». - Стерлитамак: АМИ, 2021. - С. 34-36.

2. Головина И.В., Титова О.А. Особенности организации дистанционного обучения иностранным языкам в неязыковом вузе // Научно-методический электронный журнал «Концепт». - 2016. - Т. 5. - С. 151-154.

3. Новые педагогические и информационные технологии в системе образования: [учеб. пособие для студ. пед. вузов и системы повыш. квалиф. пед. кадров] / Е.С. Полат, М.Ю. Бухаркина, М.В. Моисеева, А.Э. Петров; под ред. Е.С. Полат. - [2-е изд., стер.] - К.: Издательский центр «Академия», 2005. - 27 с.

4. Палагутина М.А., Серповская И.С. Инновационные технологии обучения иностранным языкам // Сб. материалов межд. науч.-практ. конф. «Проблемы и перспективы развития образования» (г. Пермь, апрель 2011 г.) Т. І. — Пермь: Меркурий, 2011. - С. 156-159.

5. Abduqodirov A., Pardayev A. Theory and practice of distance learning. - T.: Fan, 2009. $-257 \mathrm{p}$. 
6. Bieswanger, M. Aviation English: Two distinct specialized registers? In Schubert, Ch., Sanchez-Stockhammer, Ch. (Eds.), Variational Text Lingusitics: Revising register in English, 2016. - p. 67-85.

7. Ruzimurodov 0.N. Haydarov T. Technologies and principles of distance learning. - T.: Istiqlol, 2006. -320 p.

( ) Левичева Светлана Викторовна (parabola.08@mail.ru), Левичев Олег Анатольевич (info@guz.ru).

Журнал «Современная наука: актуальные проблемы теории и практики»

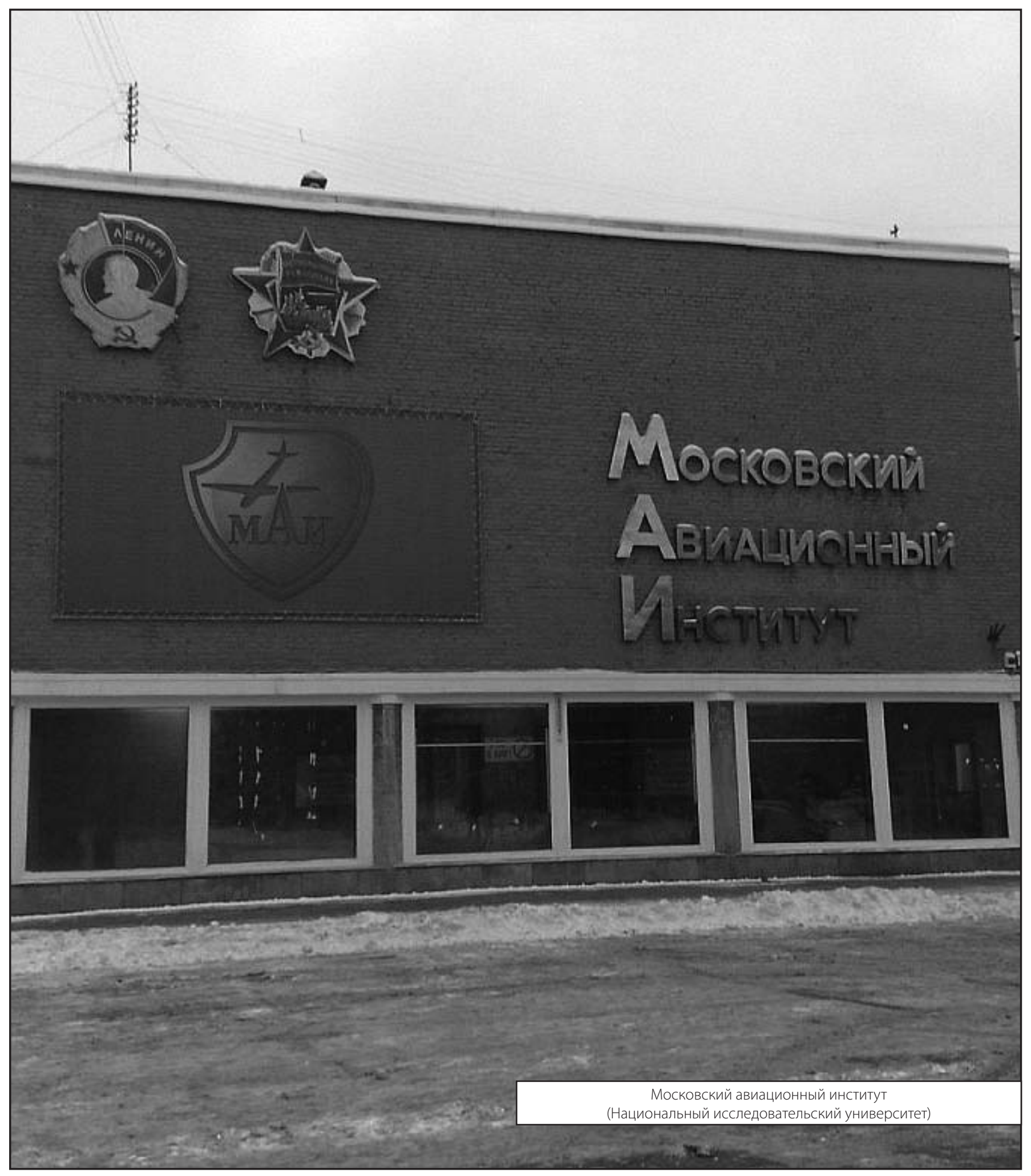

